Check for updates

\section{The BMJ}

Cite this as: BMJ 2022;376:0610 http://dx.doi.org/10.1136/bmj.0610 Published: 8 March 2022

\title{
Ukraine invasion: 16 health facilities have been attacked, WHO confirms
}

\section{Gareth lacobucci}

The World Health Organization has verified 16 reports of attacks on health facilities in Ukraine up to 8 March, as it reiterated its urgent call for a safe corridor in the country so that humanitarian workers and supplies can reach people in need. ${ }^{1}$

Speaking at a media briefing on 8 March, 13 days into the military assault by Russia, WHO’s regional director for Europe, Hans Kluge, strongly condemned the attacks on healthcare services, warning that Ukraine's health system was under "severe pressure.”

"It should not need saying that health workers, hospitals, and other medical facilities must never be a target at any time, including during crises and conflicts," he said. "To date, we have 16 confirmed reports of attacks in Ukraine, and more are being verified."

Catherine Smallwood, senior emergency officer at WHO's regional office for Europe, told the briefing that the 16 verified attacks had led to nine deaths and 16 injuries. She said the incidents had occurred in and around various cities and conflict lines, citing examples of hospitals damaged and health infrastructure and ambulances being appropriated for purposes other than the provision of healthcare. It has been reported that attacks have affected hospitals in cities including Zhytomyr, in the north west of the country, Vuhledar, near Mariupol in the south west, and Kharkiv, in the north east.

Kluge outlined WHO's three priorities, the first being to get health supplies into Ukraine through a safe passage.

"Lifesaving essential medicines, such as oxygen and insulin, personal protective equipment, surgical supplies, anaesthetics, and safe blood products are in short supply," he warned.

"So far, two shipments totalling 76 tonnes of trauma and emergency health supplies, as well as freezers, refrigerators, ice packs, and cool boxes, are in transit in Ukraine. We have further shipments of 500 oxygen concentrators, and more supplies are on their way."

Beyond Ukraine, Kluge warned that the "fastest growing refugee crisis in Europe for more than 75 years" was developing and said WHO's second priority was to help equip neighbouring countries with the infrastructure and expertise to meet the urgent healthcare needs of people arriving from Ukraine.

WHO has deployed expert teams to Hungary, Poland, the Republic of Moldova, and Romania and is coordinating closely with relevant governments and authorities and partners to assess the needs of incoming refugees, he said.
The third priority was to provide healthcare support on the ground in Ukraine, Kluge added, saying that WHO was responding to the "urgent need for trauma and injury support with rapid refresher training, supplies, and staffing through the mobilisation of medical teams."

He added that continuity of care for people with long term health needs was a "major challenge" because of the broken supply lines of medicines. The United Nations Population Fund (UNFPA) has estimated that 80 ooo women in Ukraine will give birth in the next three months without access to critical maternal care.

Re-establishing and maintaining vaccination programmes, tuberculosis and HIV treatment, and mental health services were all priorities, Kluge said. "We are working to support these essential medical needs through fixed facilities and field hospitals or mobile health services and by making key diagnostics, medicines, and medical supplies available."

Kluge added that Ukraine had reported 731 deaths from covid-19 last week. "Sadly, this number will increase as oxygen shortages continue,” he said.

Howard S. Ukraine invasion: safe corridor for medical supplies is urgently needed, says WHO. BM/2022;376:0570 doi: 10.1136/bmj.0570 pmid: 35241435 